\title{
Anatomopathological characteristics and determination of KRAS/NRAS in patients of 20-35 years with diagnosis of colorectal adenocarcinoma in the Hospital General de México from 2011 to 2015
}

\section{B. Lorena García-Romero ${ }^{1 *}, M^{a}$ Mercedes Hernández-González ${ }^{2}$ and Saulo Mendoza-Ramírez ${ }^{3}$}

${ }^{1}$ Departamento de Anatomía Patológica, Hospital General de México “Dr. Eduardo Liceaga"; ${ }^{2}$ Departamento de Patología, Hospital Regional $1^{\circ}$ de Octubre, Instituto de Seguridad y Servicios Sociales de los Trabajadores del Estado, ISSSTE; ${ }^{3}$ Departamento de Patología quirúrgica, Hospital General de México "Dr. Eduardo Liceaga". Mexico City, Mexico

\begin{abstract}
Background: The WHO (2000) defines colorectal carcinoma (CRC) as a malignant epithelial tumor. Only tumors that penetrate the muscularis mucosa toward the serosa are considered invasive tumors. CRC is one of the leading causes of malignant neoplasms of the digestive tract. It affects men and women in similar proportions, with an average age of 62 years. Recent literature points to an increase in the incidence of this neoplasm in young patients. Molecularly, two major types of colon cancers can be distinguished. The first and most frequent type (85\%) is associated with chromosomal instability by mutations in APC, Ras, and p53; while the other types are associated with the presence of microsatellite instability or alteration of specific DNA repair genes (8-12\%). Mutations in K-Ras play a very important role in tumorigenesis; in the case of CRC, somatic mutations in K-ras are found in $25-40 \%$ of the cases. The mutation status of $K$-Ras is an important predictor marker for anti-epidermal growth factor receptor (EGFR) treatment because advanced or invasive CRC harboring K-Ras mutations appear to have a worse response to treatment than those with a non-mutated or wild-type (WT) genotype. Verifying the genotype before offering and initiating treatment with anti-EGFR drugs is of utmost importance. Objective: The aim of this study was to establish the mutation status of K-RAS in young Mexican patients with invasive CRC to determine possible candidates for anti-EGFR therapy in this age group and to know the clinical-pathological features in these cases. Materials and methods: Histological specimens of 23 cases of colectomies with CRC diagnosis were analyzed. A paraffin block from each case was submitted to a molecular study by real-time polymerase chain reaction to determine the mutation status of RAS (KRAS/NRAS). Results: In 14 cases $(60.8 \%)$, KRAS/NRAS was not mutated with WT genotype; in four cases (17.3\%), the samples could not be processed and the mutation status could not be determined; and in four cases (17.3\%), mutations were found in KRAS. Conclusions: This descriptive study provides important statistical data that support CRC knowledge in the Mexican population, specifically on some clinical, histopathological, and mutational features of the Ras gene in young patients. Recent advances in molecular biology and the genetic classification of CRC are essential to individualize treatments and, in the coming years, to optimize them.
\end{abstract}

Key words: Colorectal cancer. Histopathology. Age. KRAS.

Correspondence:

*B. Lorena Garcia-Romero

E-mail: Iorenagarciaromero@ gmail.com
Date of reception: 13-06-2017

Date of acceptance: 20-10-2017

DOI: 10.24875/HGMX.M19000012
Available online: 13-09-2019 Rev Med Hosp Gen Mex. 2019;82(3):131-139

www.hospitalgeneral.mx 0185-1063/@ 2017 Sociedad Médica del Hospital General de Mexico. Published by Permanyer México SA de CV. This is an open access article under the CC BY-NC-ND license (http://creativecommons.org/licenses/by-nc-nd/4.0/). 


\section{Introduction}

The incidence of colorectal carcinoma (CRC) varies considerably". GLOBOCAN 2008 reported an incidence of 6437 cases $(5 \%)$ and a mortality of 4009 cases $(5.2 \%)$ in Mexico ${ }^{2}$; while INEGI reported 74,685 deaths from cancer in 2010 (13\% of deaths in Mexico), of which $5.4 \%$ are due to $\mathrm{CRC}^{3,4}$.

It affects both men and women in similar proportions, with an average age of 62 years ${ }^{5}$. Cases that occur in young patients ( $<40$ years of age) are located in the distal and rectum colon and tend to show features associated with more aggressive behavior or be associated with familial carcinoma syndromes ${ }^{5}$.

Some epidemiological data recorded in the years 1973-2005 have identified an increase in the annual percentage of $2.2 \%$ in CRC diagnosed in patients under the age of $40^{6}$. The percentage with a more significant change was identified in patients aged between 35 and 39 years $^{7}$. It is important to recognize this increase in the incidence of CRC in young patients, mainly because it is a rare clinical suspicion that can lead to a poor approach and an incorrect management of the patient in the early stages of the disease.

There is scarce literature regarding $\mathrm{CRC}$ in young patients, and even more, in patients under the age of 35 in the Mexican population. Some studies report an unfavorable clinical prognosis in this group of patients; others have found equivalent or better survival rates compared with elderly patients. The literature also shows variable data on the most common site; some indicate that it is more common in the right colon and others mention the distal portion of the colon as the preferred site ${ }^{7,8}$.

In the past decade, there has been an increase in the knowledge of the molecular biology of cancer, which has allowed to recognize and detect the mechanisms that cause the disease, at least in part ${ }^{9}$.

CCR is the result of a progression and accumulation of different genetic alterations. It is believed that there are several genes, including oncogenes, tumor suppressor genes, and DNA repair genes, which have a central role in carcinogenesis.

Molecularly, two large types of colon tumors can be distinguished with a different genetic origin. The first and most frequent type $(85 \%)$ is associated with chromosomal instability due to mutations in APC, Ras, and p53, while the other groups are associated with the presence of microsatellite instability or alteration of specific DNA repair genes (8-12\%). In most epithelial tumors, the activation of signaling pathways, regardless of any oncogenic alterations present, gives rise to a constitutive activation there of ${ }^{10,11}$. In colon cancer, signaling mediated by the epidermal growth factor receptor (EGFR) is thought to be either activation, increased ligands, or alterations in the factors that transmit the signal from the membrane to the nucleus, triggering an increase in tumor proliferation ${ }^{12,13}$.

In this study, we focused on detecting mutations in the Ras family of proto-oncogenes, specifically KRAS and NRAS.

The Ras family of proto-oncogenes was identified by Edward Scolnick et al. more than 30 years ago as a viral gene with oncogenic properties through several point mutations that are usually detected in carcinomas as well as in more than half of adenomas, particularly in larger ones and those with high-grade dysplasia or predominant villous component. These genes have been subdivided into three types: Harvey Ras (HRAs), neuroblastoma Ras (NRas), and Kirsten Ras (KRas), which are closely related and function in a similar way regulating cell signaling pathways associated with growth, migration, adhesion, integrity of the cytoskeleton, survival, and cell differentiation. The KRAS gene is the one with the most frequent mutation in $\mathrm{CCR}^{11,14}$.

The RAS family genes encode a series of Ras proteins under normal conditions, which transmit signaling produced by the activation of membrane receptors. In short, the inactive Ras protein is bound to GDP and, when stimulated, a guanine nucleotide exchange factor favors the formation of GTP-ras, which is the active form. Rapidly, said GTP is hydrolyzed to GDP by the intrinsic GTPase activity of Ras proteins, inactivating itself. When there are KRAS mutations, the GTPase activity is blocked and the Ras protein remains constitutively activated and bound to GTP ${ }^{12,14}$.

K-Ras mutations play a very important role in tumorigenesis, as approximately $30 \%$ of malignant neoplasms in humans have a K-Ras mutation. As for CRC, somatic mutations are $25-40 \%$, with a higher incidence rate in metastatic disease and correspond mainly to substitutions in codon 12 and 13 of exon 1 and much less frequently in codon 61 of the exon 2 which mainly affect the GTPase function of K-Ras, triggering cell proliferation even in the absence of external signals ${ }^{10,14}$. In addition, certain genotypes could be associated with worse prognosis, that is, apparently CRCs with mutations in codon 12 have shown an unfavorable prognosis, regardless of the tumor stag $\mathrm{e}^{15}$. 
However, there is not enough evidence yet defined in literature.

EGFR is a targeted therapy in the management of CRC. Studies have shown that, in addition to wild KRAS genotypes, wild NRAS genotypes are also important in response to anti-EGFR therapy. This suggests that the NRAS genotype should also be used, in conjunction with KRAS, to select patients who could benefit from receiving such treatment. The frequency of mutations in KRAS and NRAS genes is approximately $23 \%$ and $2 \%$, respectively. No significant differences were observed in KRAS and NRAS mutations with respect to sex, age, location, and clinical-pathological stage $\mathrm{e}^{16,17}$.

Mutation status is an important predictive marker for anti-EGFR treatment, as advanced or invasive CRC harboring K-Ras mutations appear to have a worse response to treatment than those with a non-mutated or wild-type (WT) genotype. Hence, it is necessary to check the genotype before offering and starting treatment with anti-EGFR drugs ${ }^{18}$.

The purpose of this study was to describe the incidence and genotype of K-RAS and N-RAS mutations in young Mexican patients with invasive CRC to determine how many could be candidates for anti-EGFR therapy in this age group.

\section{General objectives}

The general objectives of this study were as follows:

- To determine the frequency of invasive colorectal adenocarcinomas in patients aged 20-35 years and the mutation status of the RAS gene.

- Determine the number of cases of non-mutated RAS (WT) and thus the "candidates" to receive anti-EGFR therapy.

\section{Study type}

It is a retrospective, cross-sectional, descriptive, and non-experimental study.

\section{Materials and methods}

Authorization was requested in writing to the Head of the Pathology Unit of the General Hospital of Mexico "Dr. Eduardo Liceaga" to access the database and files of slides and paraffin blocks.

This is a retrospective review study of cases diagnosed as "colorectal adenocarcinoma" in patients aged 20-35 years at the General Hospital of Mexico "Dr. Eduardo Liceaga." The database showed 48 cases with this diagnosis from January 2011 to December 2015. Of the 48 cases, 25 of them corresponded to colonoscopy biopsies and 23 cases to intestinal resections (hemi/colectomies). The pathology reports showed data related to age, sex, tumor location, differentiation grades, level of invasion, and stage. The tissue samples were fixed in 10\% formaldehyde and placed in paraffin for histological analysis. All sections were stained with hematoxylin-eosin and the histological features of each tumor were evaluated.

Subsequently, a paraffin block of each case was submitted, whose slide was previously analyzed and selected for performance of a molecular study, to real-time polymerase chain reaction, to determine the mutation status of RAS (KRAS/NRAS). The results were classified into non-mutated KRAS/NRAS (WT genotype), mutated KRAS or NRAS (in which cases, genotype was specified), and non-determined KRAS/ NRAS (non-processable samples or cases that after review were not diagnosed as invasive colorectal adenocarcinomas).

\section{Results}

The database of the Surgical Pathology Service of the General Hospital of Mexico showed 473 cases of colorectal adenocarcinoma, of which only 23 cases $(4.8 \%)$ corresponded to total colectomies or hemicolectomies of patients aged 20-35 years. The median age was 32 years, the average age was 31.26 years, and the standard age was 34 years; 16 were men $(69.5 \%)$ and 7 women (30.4\%) (Table 1).

Regarding localization, 12 cases were detected in the right colon (52.1\%) and 10 cases in the left colon $(43.4 \%)$ and it was not possible to determine localization in 1 case (4.3\%) (Fig. 1).

The most common histologic grade was moderately differentiated adenocarcinoma, with 18 cases $(78.2 \%)$, followed by poorly differentiated with 3 cases $(13 \%)$ and well-differentiated with 2 cases (8.6\%) (Table 1 and Figs. 2 and 3).

Mucinous differentiation was identified only in 3 cases (13\%), in six cases, it was focal $(26 \%)$, and in 14 cases, there was no such differentiation (60.8\%). The presence of signet ring cells was observed in the three cases that showed mucinous differentiation $(13 \%)$. No signet ring cells were found in the other adenocarcinoma cases with or without focal mucinous 
Table 1. Clinical-pathological features

\begin{tabular}{|c|c|c|c|c|}
\hline Case & Gender & Age & Laterality & Histologic grade \\
\hline 1 & $\mathrm{~F}$ & 25 & Right & $\begin{array}{l}\text { Moderately } \\
\text { differentiated }\end{array}$ \\
\hline 2 & M & 34 & Right & $\begin{array}{l}\text { Moderately } \\
\text { differentiated }\end{array}$ \\
\hline 3 & $\mathrm{~F}$ & 35 & Left & Well differentiated \\
\hline 4 & M & 29 & Right & $\begin{array}{l}\text { Moderately } \\
\text { differentiated }\end{array}$ \\
\hline 5 & $\mathrm{~F}$ & 31 & Left & Poorly differentiated \\
\hline 6 & M & 29 & Right & $\begin{array}{l}\text { Moderately } \\
\text { differentiated }\end{array}$ \\
\hline 7 & M & 34 & Right & $\begin{array}{l}\text { Moderately } \\
\text { differentiated }\end{array}$ \\
\hline 8 & M & 32 & Right & Poorly differentiated \\
\hline 9 & $M$ & 34 & Right & $\begin{array}{l}\text { Moderately } \\
\text { differentiated }\end{array}$ \\
\hline 10 & $\mathrm{~F}$ & 35 & Right & $\begin{array}{l}\text { Moderately } \\
\text { differentiated }\end{array}$ \\
\hline 11 & M & 26 & Right & $\begin{array}{l}\text { Moderately } \\
\text { differentiated }\end{array}$ \\
\hline 12 & M & 30 & Left & $\begin{array}{l}\text { Moderately } \\
\text { differentiated }\end{array}$ \\
\hline 13 & $M$ & 33 & Left & $\begin{array}{l}\text { Moderately } \\
\text { differentiated }\end{array}$ \\
\hline 14 & $M$ & 35 & Left & $\begin{array}{l}\text { Moderately } \\
\text { differentiated }\end{array}$ \\
\hline 15 & M & 31 & ND & $\begin{array}{l}\text { Moderately } \\
\text { differentiated }\end{array}$ \\
\hline 16 & $\mathrm{~F}$ & 33 & Right & $\begin{array}{l}\text { Moderately } \\
\text { differentiated }\end{array}$ \\
\hline 17 & $\mathrm{~F}$ & 26 & Left & $\begin{array}{l}\text { Moderately } \\
\text { differentiated }\end{array}$ \\
\hline 18 & $\mathrm{~F}$ & 31 & Right & $\begin{array}{l}\text { Moderately } \\
\text { differentiated }\end{array}$ \\
\hline 19 & $M$ & 31 & Left & $\begin{array}{l}\text { Moderately } \\
\text { differentiated }\end{array}$ \\
\hline 20 & $M$ & 34 & Left & $\begin{array}{l}\text { Moderately } \\
\text { differentiated }\end{array}$ \\
\hline 21 & $M$ & 32 & Left & Well differentiated \\
\hline 22 & $M$ & 33 & Left & $\begin{array}{l}\text { Moderately } \\
\text { differentiated }\end{array}$ \\
\hline 23 & M & 26 & Right & Poorly differentiated \\
\hline
\end{tabular}

differentiation (20 cases that represented $86.9 \%$ ) (Fig. 4).

None of the analyzed cases showed histological heterogeneity or Crohn's-type inflammatory response.

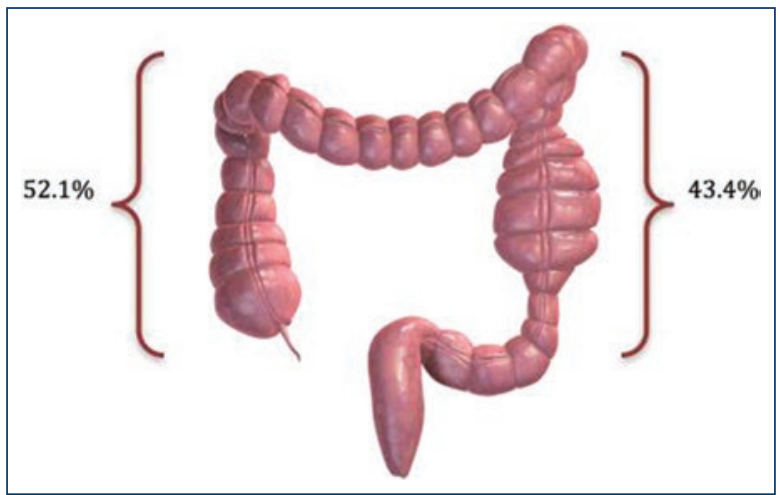

Figure 1. Percentage of colorectal carcinoma cases by localization: 12 cases were found in the right colon and 10 cases in the left colon.

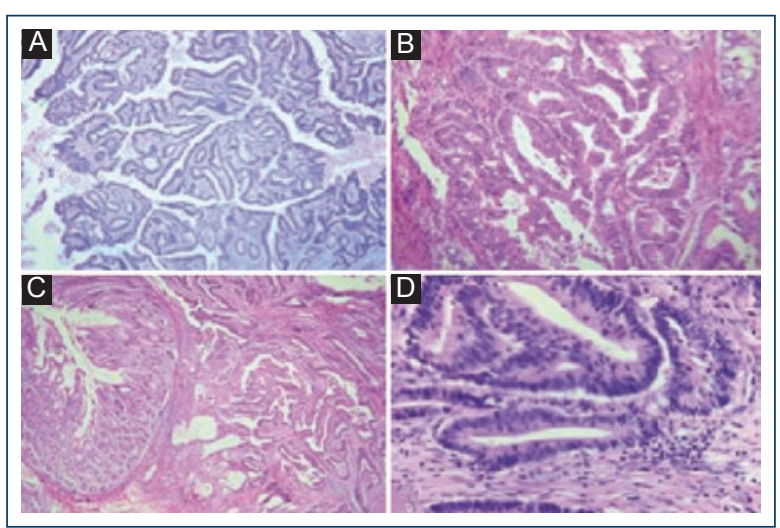

Figure 2. Histological sections stained with hematoxylineosin were observed in four of the 23 cases studied. A-D: The morphological characteristics of moderately differentiated adenocarcinomas are demonstrated; histologic grade most frequently identified.

Most neoplastic lesions showed borders with a pushing infiltration pattern with 11 cases $(47.8 \%)$, followed by the infiltrative pattern with 9 cases (39.1\%). This parameter could not be determined in 3 cases (13\%) (Fig. 5).

No tumor necrosis was identified in 13 cases $(56.5 \%)$, while focal or extensive necrosis was observed in 10 cases (43.4\%) (Fig. 6).

The amount of intratumoral lymphocytes was variable; the average was 8.4 lymphocytes in 10 high-power fields, with a range of 0-18.

As for the mutation status of KRAS/NRAS: in 14 cases $(60.8 \%), \mathrm{KRAS} / \mathrm{NRAS}$ was not mutated with WT genotype; in 4 cases (17.3\%), the samples were not processable and the mutation status could not be determined; in 4 cases (17.3\%), mutations were found in KRAS, but not in NRAS (Fig. 7 and Table 2). 


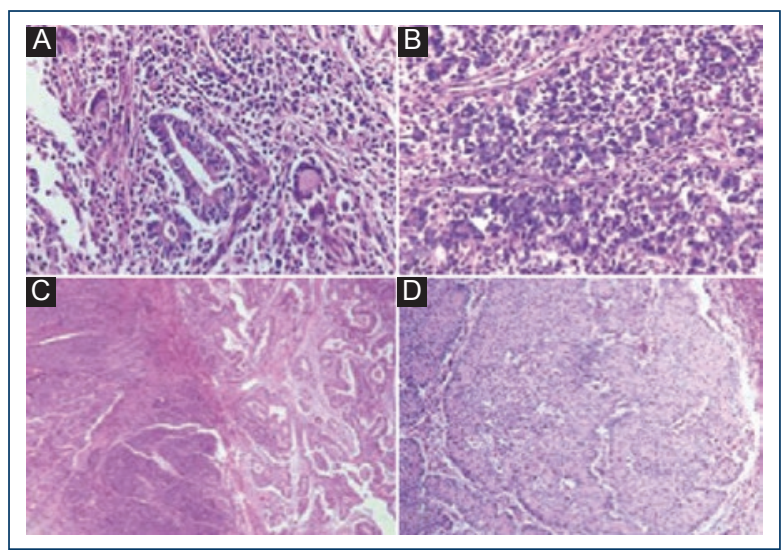

Figure 3. Histological sections stained with hematoxylineosin were observed in two of the 23 cases studied. A: Some glandular structures are identified in some fields $(\times 20) 2$ : Diffuse growth pattern in poorly differentiated adenocarcinoma $(\times 40)$. B-D: The morphological characteristics of poorly differentiated adenocarcinomas are shown.

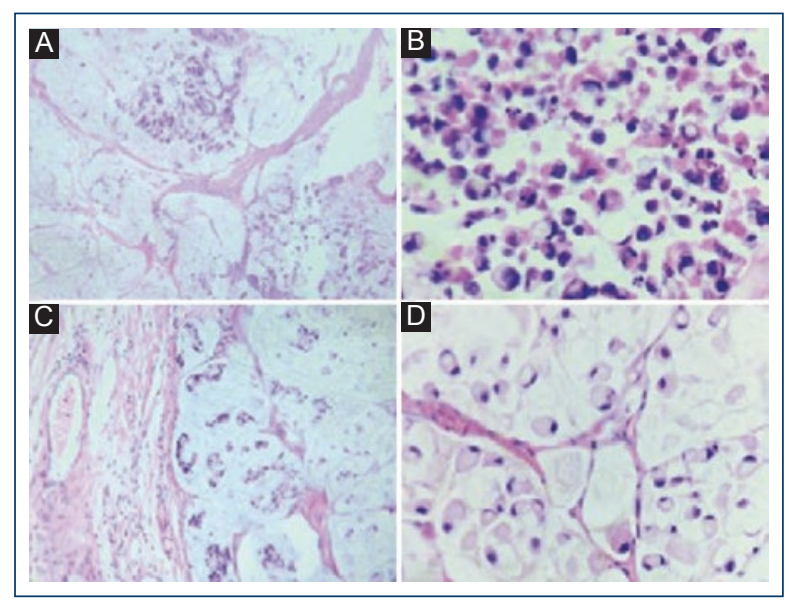

Figure 4. A-D: Histological sections stained with hematoxylin-eosin were observed in two cases with mucinous differentiation and the presence of signet ring cells. A-B: Areas with mucinous material are observed. C-D: At higher magnification, signet ring cells immersed in the mucinous material are identified.

From the genotype analysis of the samples, three different polymorphisms were found; two cases presented transversion at position $35(\mathrm{G}>\mathrm{T})$, which generated a change of amino acid G12V (glycine to valine) in the KRAS protein. The following case presented $C>A$ transversion in position 181 , whose consequence was the change of amino acid Q61K (glutamine to lysine). In the last identified case, a $G>A$ transition was detected at position 35 that resulted in the change of amino acid G12D (glycine to aspartic acid) (Table 3).

\section{Discussion}

CRC is recognized as a typical entity of adults, generally, when patients are in their sixties or older, with more than $90 \%$ of cases diagnosed in patients older than 55 years. There are no detailed or constant statistical data on this neoplasm in young adults. There is no consensus on the cutoff age to consider a patient as "young;" some articles propose 40 years as the cutoff age to define young patients with $\mathrm{CRC}$; others report patients under 50 years; while other articles mention patients under 30 years or cases in adolescents $^{19,20}$. Thus, we wanted to include young patients aged between 20 and 35 years old in our study.

The prevalence of CRC in young people is variable and is reported between $2 \%$ and $10 \%{ }^{21}$. Ciarrocchi et al. ${ }^{19}$ conducted a review of articles published in PubMed over a period of 20 years on "colorectal carcinoma in young people," to analyze if in these cases, said neoplasm represents a specific or totally distinguished medical condition in terms of etiology and pathogenesis. They also attempted to ensure whether the presentation in more advanced stages was the result of the biological aggressiveness of the tumor or due to a delayed diagnosis, and how this situation affected the prognosis. They encountered some difficulties to perform an adequate meta-analysis. The most relevant were the heterogeneity in the definition of "young patient" and the few cases of CRC in this age group, which makes the design of prospective studies difficult. The published articles are, for the most part, retrospective studies or case reports; therefore, their results cannot be applied to the general population ${ }^{19}$. Ciarrocchi et al. ${ }^{19}$ concluded that CRC in young patients is probably a different condition characterized by aggressive behavior. Notwithstanding, groups of young patients show the same or even better survival rates compared to older patients, due to an overall better condition, which allows for a more aggressive treatment scheme.

They reported, like in other articles, that the incidence of CRC in patients aged between 20 and 40 years old is on the rise $\mathrm{e}^{19,20,22}$, and therefore, medical attention is mandatory to obtain an early diagnosis, as diagnosis in an advanced stage is per se an unfavorable prognostic factor in all age groups ${ }^{19}$. Other factors, in addition to the aggressive behavior of the neoplasm, which may contribute to the perception of a worse prognosis for young patients, are the lack of screening tests for this age group, delayed diagnosis, and, consequently, lesions in more advanced stages. However, studies indicate that differences in survival rates and disease-free 


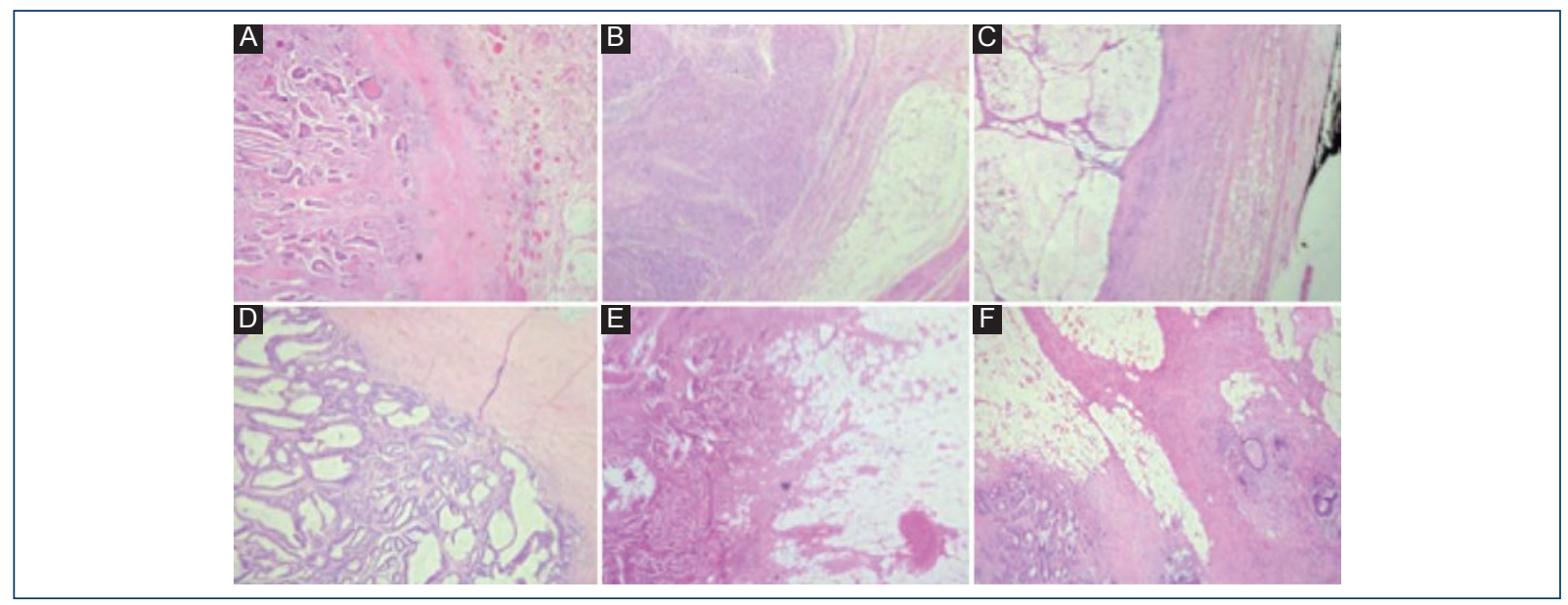

Figure 5. Histological sections stained with hematoxylin-eosin were observed in six cases. A-D: Correspond to lesions that show border with a pushing pattern. E-F: Infiltrating growth pattern.

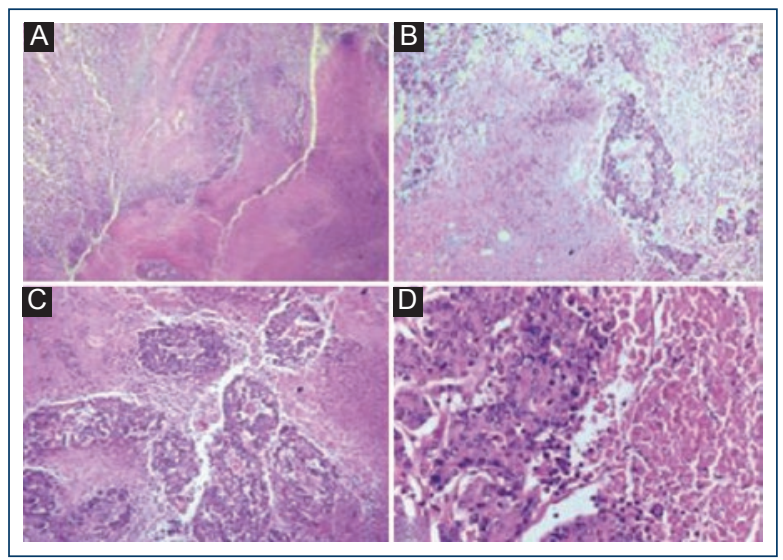

Figure 6. A-D: Histological sections stained with hematoxylin-eosin were observed in four of the 10 cases with focal or extensive necrosis.

survival rates are subtle and even similar in young and older patients ${ }^{22,23}$.

Some articles highlight differences and similarities in certain clinical-pathological features in cases of young patients versus older patients. For example, there is a higher frequency of poorly differentiated, mucinous adenocarcinomas, with signet ring cells, lymphovascular invasion, advanced stages, and lymph node metastasis in young patients ${ }^{22,24}$.

Some of the clinical-pathological features found in our study differed from reported statistics, for instance, in our small series of cases, the most frequent localization was the right colon, the most frequent histologic grade was moderately differentiated adenocarcinoma, 3 cases (13\%) were poorly differentiated and only three cases

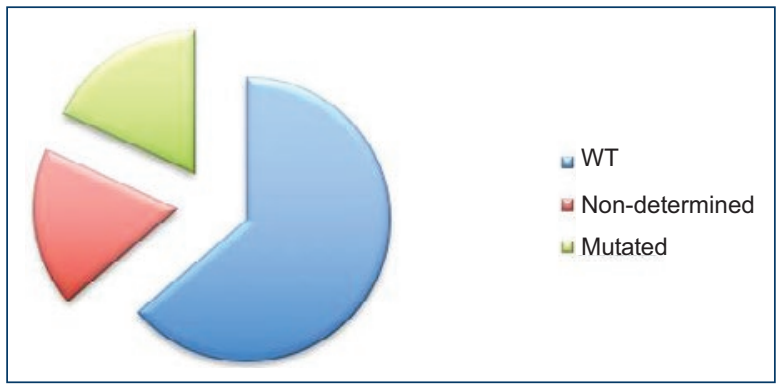

Figure 7. KRAS mutation status: wild-type genotype was found in $60.8 \%$; in $17.3 \%$, the mutation status could not be determined and $17.3 \%$ mutations were found in KRAS.

had mucinous differentiation with the presence of signet ring cells.

As for the mutation status of K-Ras, oncogenic mutations are reported in $40 \%$ (20-50\%) of CRC cases. Most mutations (90\%) are in codons 12 and 13 , less frequently in codon $61^{25}$. This coincides with the results of our study, in which codon 12 was affected in three cases and codon 61 in one case (Table 3).

In recent studies, it has been suggested that the mutation status of RAS and mutations in specific codons, in addition to being important to determine the response or resistance to anti-EGFR therapy ${ }^{26}$, could have prognostic significance and be associated with some particular clinical-pathological features.

Bazan et al. ${ }^{25}$ conducted a prospective study with 160 CRC cases, determined the mutation status of K-Ras, and decided to establish the prognostic significance and its possible relationship with some clinical-pathological 
Table 2. RAS mutation status (KRAS/NRAS)

\begin{tabular}{|c|c|c|c|c|c|c|}
\hline Case & Gender & Age & Laterality & Histologic grade & KRAS status & NRAS Status \\
\hline 1 & $\mathrm{~F}$ & 25 & Right & Moderately & Mutated & \\
\hline 2 & $M$ & 34 & Right & Moderately & WT & WT \\
\hline 3 & $\mathrm{~F}$ & 35 & Left & Well & ND & \\
\hline 4 & $M$ & 29 & Right & Moderately & WT & WT \\
\hline 5 & $\mathrm{~F}$ & 31 & Left & Poorly & WT & WT \\
\hline 6 & $M$ & 29 & Right & Moderately & ND & ND \\
\hline 7 & $M$ & 34 & Right & Moderately & WT & WT \\
\hline 8 & $M$ & 32 & Right & Poorly & ND & ND \\
\hline 9 & $M$ & 34 & Right & Moderately & Mutated & ND \\
\hline 10 & $\mathrm{~F}$ & 35 & Right & Moderately & WT & WT \\
\hline 11 & $\mathrm{M}$ & 26 & Right & Moderately & WT & WT \\
\hline 12 & $M$ & 30 & Left & Moderately & ND & ND \\
\hline 13 & $M$ & 33 & Left & Moderately & WT & WT \\
\hline 14 & $\mathrm{M}$ & 35 & Left & Moderately & ND & ND \\
\hline 15 & $M$ & 31 & ND & Moderately & WT & WT \\
\hline 16 & $\mathrm{~F}$ & 33 & Right & Moderately & WT & WT \\
\hline 17 & $\mathrm{~F}$ & 26 & Left & Moderately & WT & WT \\
\hline 18 & $\mathrm{~F}$ & 31 & Right & Moderately & WT & WT \\
\hline 19 & $M$ & 31 & Left & Moderately & Mutated & ND \\
\hline 20 & $M$ & 34 & Left & Moderately & WT & WT \\
\hline 21 & $M$ & 32 & Left & Well & Mutated & ND \\
\hline 22 & $\mathrm{M}$ & 33 & Left & Moderately & WT & WT \\
\hline 23 & $M$ & 26 & Right & Poorly & WT & WT \\
\hline
\end{tabular}

Table 3. KRAS clinical features and genotypes

\begin{tabular}{|l|l|l|l|l|l|}
\hline Case & Gender & Age & Laterality & KRAS status & Genotype \\
\hline 1 & F & 25 & Right & Mutated & C.35G $>$ T (P.G12V) \\
\hline 9 & M & 34 & Right & Mutated & C.181C $>$ A (P.061K) \\
\hline 19 & M & 31 & Left & Mutated & C.35G $>$ A (P.G12D) \\
\hline 21 & M & 32 & Left & Mutated & C.35G $>$ T (P.G12V) \\
\hline
\end{tabular}

features. They showed an association between specific mutations in codon 13 and cases in advanced clinical stages and metastases in lymph nodes, suggesting their direct participation in tumor progression and aggressiveness. They also found that mutations in codon
12, whose effect on RAS function was deemed similar to cases with mutation in codon 13 , are associated with the mucinous adenocarcinoma histotype. This suggests that specific mutations in codon 12 preferably affect signal transduction pathways involved in the regulation 
Table 4. Histopathological features of cases with KRAS mutation

\begin{tabular}{|l|l|l|l|l|l|l|l|}
\hline Case & Gender & Laterality & $\begin{array}{l}\text { Mutated KRAS } \\
\text { Genotype }\end{array}$ & Histologic grade & Mucinous differentiation & $\begin{array}{l}\text { Signet } \\
\text { ring cells }\end{array}$ & Necrosis \\
\hline 1 & F & Right & C.35G $>$ T (P.G12V) & Mod & Focal & No & Absence \\
\hline 9 & M & Right & C.181C $>$ A (P.061K) & Mod & Yes & Si & Absence \\
\hline 19 & M & Left & C.35G $>$ A (P.G12D) & Mod & Focal & No & Presence \\
\hline 21 & M & Left & C.35G $>$ T (P.G12V) & Well & No & No & Presence \\
\hline
\end{tabular}

Mod: moderately differentiated.

of mucin production in the colonic mucosal cells, while their association with altered cell proliferation rates was not proven ${ }^{25}$.

According to our results, out of four cases with mutations in KRAS, three had a moderately differentiated histologic grade, the other case was well-differentiated; one case showed mucinous differentiation with the presence of signet ring cells, two cases had focal mucinous differentiation without the presence of signet ring cells, and one case had none of these two characteristics. Only one case was presented in a female patient, the other three cases were in men (Table 4).

Clinical trials verified that mutations of the K-Ras gene were related to resistance to cetuximab and other anti-EGFR therapies in patients with metastatic colorectal cancer. In our study, of 23 cases analyzed, only four cases had a K-Ras mutation; these would not benefit from anti-EGFR therapy.

It is still controversial whether the K-Ras gene mutation affects the survival rate of patients receiving adjuvant chemotherapy. Some studies reported that patients with CRC and with the WT K-Ras gene had a significantly greater benefit from chemotherapy than those with the codon 12 mutation. Other studies whose objective is to clarify whether the K-Ras mutation could affect prognosis of $\mathrm{CRC}$ patients who received adjuvant chemotherapy and the possibility of being used as a predictive biomarker for chemotherapy, have concluded that more studies are needed to establish the relationship between specific K-Ras mutation and clinical prognosis ${ }^{27}$.

\section{Conclusions}

$\mathrm{CRC}$ is a rare neoplasm in patients under 40 years of age, which makes it difficult to design and conduct prospective studies that provide us with accurate statistical data on certain clinical-pathological features to reach conclusive evidence that can be applied to the general population. Most data on the clinical and histopathological features of CRC are of adults in their fifties. In young adults, statistics is variable and there is no consensus.

This descriptive study provides important statistical data that further knowledge on CRC in the Mexican population, specifically about some clinical, histopathological features and the mutation status of the Ras gene in young patients.

In conclusion, we must emphasize the importance of the clinical suspicion of CRC, even in young patients, because a timely diagnosis helps improve both prognosis and survival rate.

Recent advances in molecular biology and the genetic classification of the CRC are essential to individualize treatments and, in the coming years, to optimize them.

We must point out that our study is descriptive. However, it aims to encourage the study of CRC in young population, know some of its specific features and promote the use of molecular tests that are important for the choice of therapeutic schemes.

\section{Acknowledgments}

We thank the General Hospital of Mexico for allowing us to make this article.

\section{Conflicts of interest}

This manuscript has no conflicts of interest and has not received funds from any institution for its performance.

\section{Ethical disclosures}

Protection of human and animal subjects. The authors declare that no experiments were performed on humans or animals for this study. 
Confidentiality of data. The authors declare that they have followed the protocols of their work center on the publication of patient data.

Right to privacy and informed consent. The authors declare that no patient data appear in this article.

\section{References}

1. Brambilla E, Travis WD, Colby TV, Corrin B, Shimosato Y. Pathology and genetics of tumors of the digestive system. World Health Organization classification. Eur Respir J. 2001;18:1059-68.

2. International Agency for Research on Cancer. Globocan; 2008. UICC/ WHO. Available from: http://www.uicc.org/resources/globocan.

3. Tovar MR. Cáncer de Colon. Oncología. Guías Diagnósticas. Hospital General de México; 2013. p. 1-4. Available from: http://www.hgm.salud. gob.mx/descargas/pdf/area_medica/onco/cancer_Colon.pdf.

4. Aldaco-Sarvide $F$, Pérez-Pérez $P$, Cervantes-Sánchez $G$, Torrecillas-Torresd L, Erazo-V AE. Mortalidad por cáncer en México 20002010: el recuento de los daños. Gac Mex Oncol. 2016;1:371-9.

5. Rosai J. Rosai and Ackerman's Surgical Pathology. $10^{\text {th }}$ ed. México: Elsvier; 2013.

6. Cunningham D, Atkin W, Lenz HJ, Lynch HT, Minsky B, Nordlinger B et al. Colorectal cancer. Lancet. 2010;375:1030-47.

7. Chang DT, Pai RK, Rybicki LA, Dimaio MA, Limaye M, Jayachandran P et al. Clinicopathologic and molecular features of sporadic early-onse colorectal adenocarcinoma: an adenocarcinoma with frequent signet ring cell differentiation, rectal and sigmoid involvement, and adverse morphologic features. Mod Pathol. 2012;25:1128-39.

8. Deen KI, Silva H, Deen R, Chandrasinghe PC. Colorectal cancer in the young, many questions, few answers. World J Gastrointest Oncol. 2016:8:481-8.

9. Munteanu I, Mastalier B. Genetics of colorectal cancer. J Med Life. 2014;7:507-11.

10. Arias A, Lucía B, Restrepo G, Uribe N, Jhony BF. Cancer colorrectal: una mirada clínica, genética y molecular. Arch Med. 2013;13:208-19.

11. Catalan V, Honorato B, García F, Bandres E, Zabalegui N, Zarate R, et al. Carcinogénesis colónica: proceso de transformación neoplásica. Rev Med Univ Navarra. 2003:47:15-9.

12. Dienstmann R, Salazar R, Tabernero J. The evolution of our molecular understanding of colorectal cancer: what we are doing now, what the future holds, and how tumor profiling is just the beginning. Am Soc Clin Oncol Educ Book. 2014;34:91-9.
13. Li Z, Liu XW, Chi ZC, Sun BS, Cheng Y, Cheng LW, et al. Detection of $\mathrm{K}$-ras mutations in predicting efficacy of epidermal growth factor receptor tyrosine kinase (EGFR-TK) inhibitor in patients with metastatic colorectal cancer. PLoS One. 2015;10:e0101019.

14. Hernández-Losa J, Sanz J, Landolfi S, López-Ríos F, Palacios J, Bautista MD, et al. Recomendaciones para la determinaciónn de mutaciones de K-RAS en cáncer de colon. Rev Esp Patol. 2012;45:76-85.

15. Gurzu S, Szentirmay Z, Jung I. Molecular classification of colorectal cancer: a dream that can become a reality. Rom J Morphol Embryol. 2013;54:241-5.

16. Taniguchi H, Yamazaki K, Yoshino T, Muro K, Yatabe Y, Watanabe T, et al. Japanese society of medical oncology clinical guidelines: ras (KRAS/NRAS) mutation testing in colorectal cancer patients. Cancer Sci. 2015;106:324-7.

17. Cree IA. Diagnostic RAS mutation analysis by polymerase chain reaction (PCR). Biomol Detect Quantif. 2016;8:29-32.

18. Chaiyapan W, Duangpakdee $P$, Boonpipattanapong T, Kanngern S, Sangkhathat S. Somatic mutations of K-ras and BRAF in thai colorectal cancer and their prognostic value. Asian Pac J Cancer Prev. 2013;14:329-32.

19. Ciarrocchi A, Amicucci G. Sporadic carcinoma of the colon-rectum in young patients: a distinct disease? A critical review. J Gastrointest Cancer. 2013;44:264-9.

20. O'Connell JB, Maggard MA, Liu JH, Etzioni DA, Livingston $\mathrm{EH}, \mathrm{Ko} \mathrm{CY}$, et al. Rates of colon and rectal cancers are increasing in young adults. Am Surg. 2003;69:866-72.

21. Iriñiz AM, Bentolilla A, Mongelos FP. Cáncer colorrectal en pacientes menores de 40 años : la edad como variable del pronóstico. Rev Mex Coloproctol. 2009;15:32-4.

22.Ganapathi S, Kumar D, Katsoulas N, Melville D, Hodgson S, Finlayson C, et al. Colorectal cancer in the young: trends, characteristics and outcome. Int J Colorectal Dis. 2011;26:927-34.

23. Li M, Li JY, Zhao AL, Gu J. Do young patients with colorectal cancer have a poorer prognosis than old patients? J Surg Res. 2011;167:231-6.

24. Chou CL, Chang SC, Lin TC, Chen WS, Jiang JK, Wang HS, et al Differences in clinicopathological characteristics of colorectal cancer between younger and elderly patients: an analysis of 322 patients from a single institution. Am J Surg. 2011;202:574-82.

25. Bazan V, Migliavacca M, Zanna I, Tubiolo C, Grassi N, Latteri MA, et al. Specific codon $13 \mathrm{~K}$-ras mutations are predictive of clinical outcome in colorectal cancer patients, whereas codon 12 K-ras mutations are associated with mucinous histotype. Ann Oncol. 2002;13:1438-46.

26. Kelley RK, Van Bebber SL, Phillips KA, Venook AP. Personalized medicine and oncology practice guidelines: a case study of contemporary biomarkers in colorectal cancer. J Natl Compr Canc Netw. 2011;9:13-25.

27. Rui YY, Zhang D, Zhou ZG, Wang C, Yang L, Yu YY, et al. Can K-ras gene mutation be utilized as prognostic biomarker for colorectal cancer patients receiving chemotherapy? A meta-analysis and systematic review. PLoS One. 2013;8:e77901. 